\title{
SERRA DO GANDARELA: POSSIBILIDADE DE AMPLIAÇÃO DAS UNIDADES DE CONSERVAÇÃO NO QUADRILÁTERO FERRÍFERO-MG ${ }^{1}$
}

\author{
Wanderson Lopes Lamounier ${ }^{2}$ \\ Vilma Lúcia Macagnan Carvalho ${ }^{3}$ \\ André Augusto Rodrigues Salgado ${ }^{4}$
}

\begin{abstract}
Resumo: O Quadrilátero Ferrífero, localizado na região centro-sudeste de Minas Gerais, se destaca nacionalmente por suas riquezas naturais, e abriga em seu interior áreas de grande relevância para a preservação ambiental. Sendo assim, tendo em vista a necessidade de preservar melhor seu rico acervo natural, o presente trabalho tem como objetivo fazer um levantamento do patrimônio natural da Serra do Gandarela, localizada no interior do Quadrilátero Ferrífero, e avaliar seu potencial para se transformar em uma Unidade de Conservação. Diante disso, foi feito um levantamento das principais características físicas, biológicas e paisagísticas da Serra do Gandarela e seu entorno. Os resultados demonstraram, além de uma área ainda muito conservada, um ambiente com ecossistemas altamente diversificados, com existência de um forte entrelaçamento entre as variáveis físicas e biológicas, bem como uma área de grade potencialidade para realização de pesquisas científicas, práticas de educação ambiental e desenvolvimento do turismo. Assim, diante dos resultados obtidos nesta pesquisa, foi possível identificar que a Serra do Gandarela e seu entorno é uma área prioritária para a conservação no interior do Quadrilátero Ferrífero. Por fim, os resultados apontaram para a necessidade de criação de unidades de conservação na área, em especial um Parque Nacional.
\end{abstract}

Palavras-Chave: Quadrilátero Ferrífero; Serra do Gandarela; Análise Ambiental; Unidades de Conservação.

\section{SERRA DO GANDARELA: POSSIBILITY OF AMPLIFICATION THE CONSERVATION UNITS IN THE QUADRILÁTERO FERRÍFERO-MG}

\begin{abstract}
The Quadrilátero Ferrifero, located in the middle-southeast region of Minas Gerais is detached nationally by its natural richness and it shelters important areas to environmental preservation. So, there is a necessity to preserve better its rich natural lot and this work intends to make a research about the natural Serra do Gandarela heritage, located into the Quadrilátero Ferrifero, and this work will evaluate its potential of transformation in the unity of conservation. Then, was made a survey about the main physical, biological and landscapes attributes of the Serra do Gandarela and its close areas. The result showed, beyond a preserved area, there are several diversity and richly ecosystems there, and one it

\footnotetext{
${ }^{1}$ Artigo elaborado a partir da dissertação: LAMOUNIER, W. L. Patrimônio natural da Serra do Gandarela e seu entorno: análise ambiental como subsídio para a criação de unidades de conservação no Quadrilátero Ferrífero - Minas Gerais. 2009, 152 f. Dissertação (Mestrado em Geografia). Instituto de Geociências, Universidade Federal de Minas Gerais, Belo Horizonte.

${ }^{2}$ Instituto Federal do Tocantins - E-mail: wandersonbiogeo@yahoo.com.br

${ }^{3}$ Universidade Federal de Minas Gerais - E-mail: vilmageografia97@gmail.com

${ }^{4}$ Universidade Federal de Minas Gerais - E-mail: Geosalgado@yahoo.com.br

DOI: 10.7154/RDG.2011.0022.0009
} 
present a strong relation with others, into its physical and biologic variable. And, there is a large potentiality to scientific researches, an environmental education practice, and to develop tourism there. Therefore, in front of the result of this research was possible to identify that the Serra do Gandarela and its close areas are important places to be conserved into the center of Quadrilátero Ferrifero. So, the result shows the necessity to create an conservation unit in this area, for example a National Park.

Key Words: Quadrilátero Ferrífero; Serra do Gandarela; Environmental Analysis; Conservation Units.

\section{INTRODUÇÃO}

O Quadrilátero Ferrífero (Figura 1) constitui uma das mais importantes regiões mineradoras do Brasil. Foi inicialmente ocupado durante o ciclo do ouro, que teve seu auge no século XVIII. Com a decadência do ouro nos aluviões, deu-se início a exploração do minério de ferro na região. Atualmente, além de abrigar grandes minerações de ferro e ouro, no Quadrilátero Ferrífero também estão presentes vários empreendimentos que exploram jazidas de outros tipos de rochas e minerais, como por exemplo, topázio e bauxita.

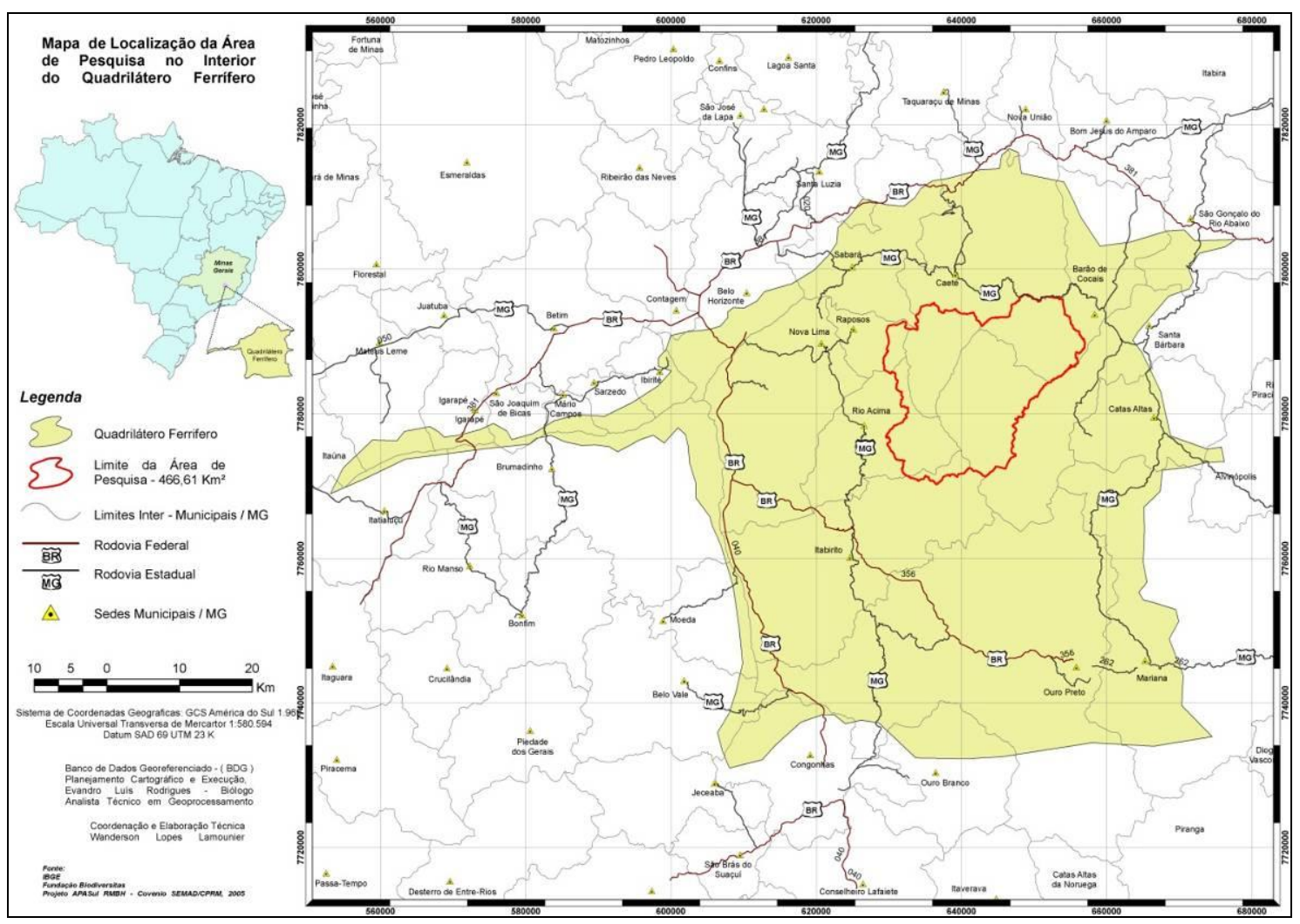

Figura 1: Mapa de localização do Quadrilátero Ferrífero (Serra do Gandarela e seu entorno em destaque) 
Serra do Gandarela: Possibilidade de Ampliação das Unidades de Conservação no Quadrilátero Ferrífero-MG Wanderson Lopes Lamounier, Vilma Lúcia Macagnan Carvalho e André Augusto Rodrigues Salgado

Entretanto, o Quadrilátero Ferrífero também é bem conhecido por seus aspectos naturais e de grande beleza cênica. Destaca-se no contexto estadual por se tratar de um ambiente único no estado, sobretudo, pela presença de campos rupestres hematíticos. Além dos aspectos físicos, a região abriga muitas espécies endêmicas e muitas ameaçadas de extinção, já identificadas em alguns poucos estudos, sendo por isso, definida como prioritária para a conservação (DRUMMOND et al., 2005).

Apesar da riqueza mineral e da grande extração que vem ocorrendo por muitos anos na região, algumas áreas ainda se encontram em condições ambientais de notável conservação, com pouca ou quase nenhuma atividade antrópica. Encontra-se no interior destas áreas belas paisagens com relevo acidentado, vales profundos, quedas d'água de tamanhos variados e rica biodiversidade.

Neste contexto, a Serra do Gandarela e seu entorno (Figura 1) - com aproximadamente 467 $\mathrm{km}^{2}$ de área - localizada a cerca de $65 \mathrm{~km}$ de Belo Horizonte, tem grande destaque na região. A sua escolha como área de estudo levou em consideração inúmeros fatores, sobretudo, o alto grau de conservação, as belezas naturais, a alta biodiversidade, a riqueza paisagística e a presença de inúmeras nascentes encontradas em seus limites, divididas em duas importantes Bacias Hidrográficas: Rio das Velhas/ São Francisco e Bacia do Rio Piracicaba/ Doce.

Como a região do Quadrilátero Ferrífero sofre intensamente com as pressões antrópicas advindas, sobretudo da mineração, faz-se necessário avaliar de forma criteriosa áreas com grande importância ambiental no seu interior, servindo, assim, de subsídio para ações de planejamento futuro na criação de novas unidades de conservação. Estas novas unidades de conservação visam garantir de forma mais efetiva seu rico acervo natural. Diante disso, esse trabalho tem como objetivo levantar as riquezas naturais da Serra do Gandarela e avaliar seu potencial para se transformar em Unidade de Conservação (UC).

\section{MATERIAIS E MÉTODOS}

A realização deste trabalho e seus procedimentos metodológicos passaram pelas seguintes etapas: levantamento bibliográfico; levantamento de dados secundários; busca de arquivos digitais para produção de mapas; e trabalhos de campo.

O levantamento bibliográfico permitiu buscar trabalhos de relevância no Quadrilátero Ferrífero, sobretudo aqueles com enfoque na região da Serra do Gandarela. O levantamento 
das principais informações de espécies da fauna e flora, encontradas nos limites da área ou em seu entorno, foi obtido através de Estudos de Impactos Ambientais (EIA) e de Relatórios de Impactos Ambientais (RIMA) de empreendimentos dentro dos limites da área ou que fazem fronteira com ela. Para isso, foi feito um levantamento prévio na Fundação Estadual do Meio Ambiente (FEAM) de todos os empreendimentos cadastrados nos municípios integrantes da área de estudo.

A produção dos mapas temáticos, tanto para a caracterização da área quanto no mapeamento de alguns resultados, contou com o auxílio da cartografia digital. Todos os dados foram obtidos em arquivos passíveis de serem trabalhados no programa ArcGis 9.2. As informações digitais foram obtidas de diversas fontes, tais como: Instituto Brasileiro de Geografia e Estatística (IBGE); Companhia de Pesquisa de Recursos Minerais (CPRM) e Fundação Biodiversitas.

Os trabalhos de campo foram realizados entre julho de 2007 e janeiro de 2009. A área foi percorrida várias vezes, a sua maioria com o auxílio de um guia local. Os objetivos desta etapa foram:

- Estabelecer os limites da área e os pontos de coleta de água para análise;

- Localizar e caracterizar os principais atrativos turísticos naturais;

- Avaliar o estado de conservação da área de uma forma geral, para auxílio de discussões posteriores, bem como evidenciar informações mais detalhadas da área.

As amostras de água foram coletadas no meio do canal, na porção média da coluna d'água. Foram utilizadas garrafas plásticas de $500 \mathrm{ml}$ previamente homogeneizadas com água destilada. Posteriormente foram acondicionadas em recipientes refrigerados e encaminhadas no mesmo dia aos Laboratórios de Geoquímica Ambiental e de Geomorfologia do Instituto de Geociências da UFMG, para análise de diversos elementos químicos e para análise de $\mathrm{pH}$, condutividade, turbidez e carga suspensa. As amostras foram analisadas segundo o Standard Methods for the examination of water and wastewater.

Paralelamente aos trabalhos de campo os atrativos turísticos naturais foram sendo registrados, ambos com o uso de máquina digital Sony $3.2 \mathrm{mp}$ Cyber-Shot e suas coordenadas geográficas com o uso do GPS Garmin Etrex. 


\section{RESULTADOS E DISCUSSÃO}

\section{O ambiente físico da Serra do Gandarela}

Assim como em todo o Quadrilátero Ferrífero a Serra do Gandarela se destaca pela diversidade do substrato geológico, com destaque para as rochas do Supergrupo Minas e Supergrupo Rio das Velhas. Estes supergrupos são compostos por variados litotipos, com destaque para os quartzitos, itabiritos, xistos, filitos, rochas carbonáticas, granitos-gnaisses e cangas, entre outras (Figura 2). Em termos estruturais a área é marcada pela Sinclinal Gandarela que se orienta segundo a direção NE-SW, com estilos estruturais distintos a sudoeste e nordeste (RUCHKYS, 2007).

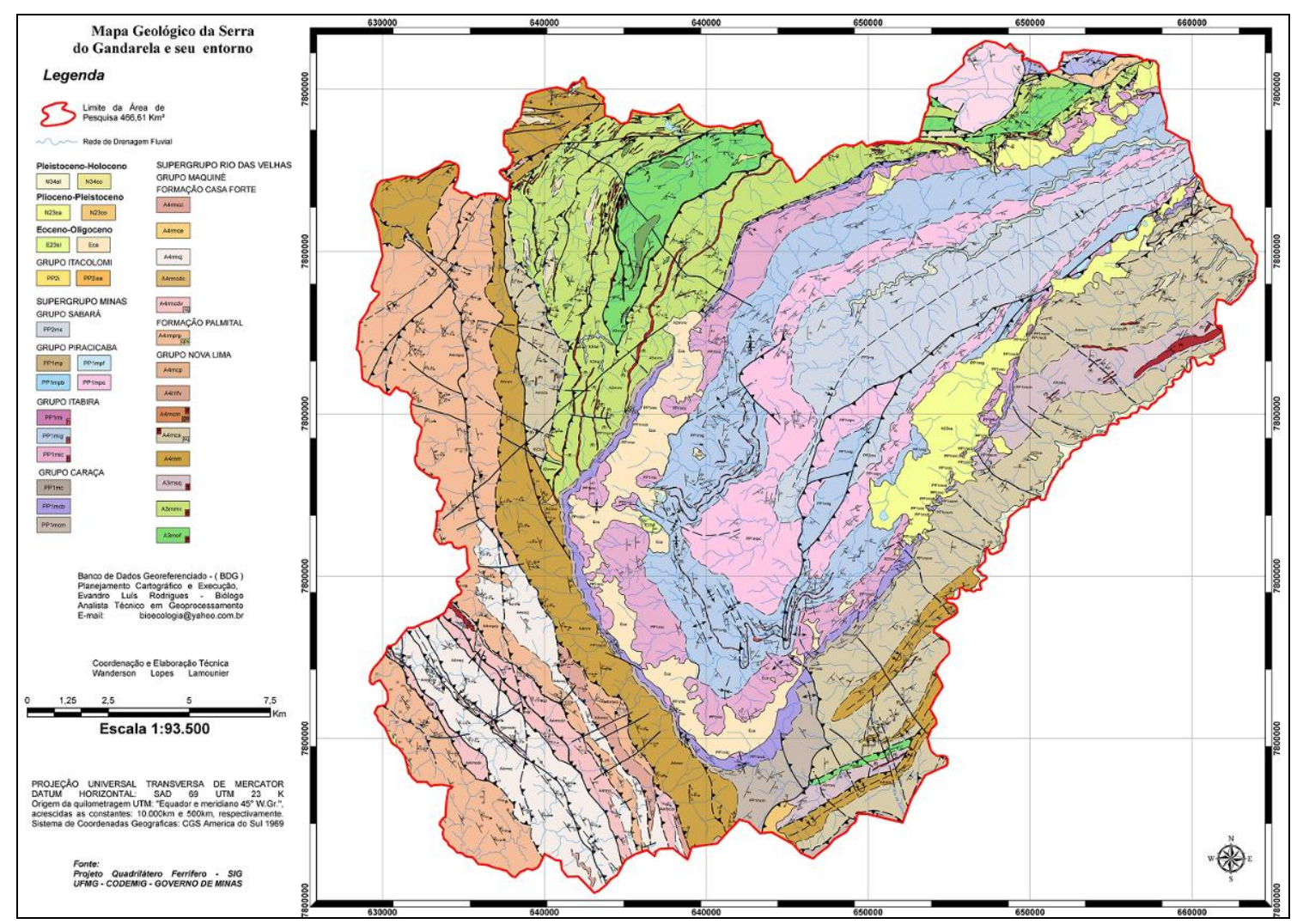

Figura 2: Mapa geológico da Serra do Gandarela e seu entorno

Ruchkys (2007) cita ainda que o Quadrilátero Ferrífero tem potencial para a Criação de um Geoparque da UNESCO e menciona que os carbonatos da Sinclinal Gandarela são um importante sítio geológico de registro Proterozóico. Isto ocorre, pois a análise da composição isotópica do carbono presente nessas rochas pode ser a base para a compreensão de estudos de fenômenos geológicos pretéritos, pois registram mudanças 
ambientais como variação no nível do mar, mudanças climáticas e evolução de certos grupos de seres vivos.

Além dessas rochas Proterozóicas, a Serra do Gandarela abriga uma importante Bacia Sedimentar. Maizatto (2001) registrou alguns traços fósseis importantes na Bacia Terciária do Gandarela, que demonstra a necessidade de se preservar a área para que futuros trabalhos sejam realizados, fomentando a pesquisa científica e ao mesmo tempo promovendo a conservação ambiental. Em estudos anteriores o mesmo autor registrou na área, através de aspectos bioestrastigráficos e paleoecológicos, a ocorrência de 113 espécies associadas a algas, pteridófitas, angiospermas, gimnospermas, artrópodes e anelídeos (MAIZZATO, 1997 apud MAIZZATO, 2001). Acrescenta ainda que, em se tratando de depósitos sedimentares continentais, ela apresenta uma posição de destaque pelo fato da ocorrência única de três unidades cronoestratigráficas empilhadas, além da grandiosidade de registro fóssil de vegetais, representado por impressões foliares carbonizadas dos mais variados grupos vegetais e elementos microscópicos como grãos de pólen, esporos e algas. Dada a sua importância, desde setembro de 2000, o autor vem buscando mecanismos para inserção do Sítio Geológico da Bacia do Gandarela na lista de patrimônio mundial da Organização das Nações Unidas para a Educação, a Ciência e a Cultura (UNESCO).

Todo esse patrimônio geológico foi ao longo de milhões de anos sendo esculpido pelos processos erosivos. De acordo com Salgado et al. $(2004 ; 2008)$ em todo o Quadrilátero Ferrífero ocorre um intemperismo e uma erosão diferencial, onde: (i) os quartzitos e itabiritos são as rochas mais resistentes e constituem o substrato das porções superiores do relevo, (ii) os xistos-filitos e granito-gnaisses as de resistência mediana, sendo que os primeiros sustentam as porções intermediárias e os últimos as porções mais rebaixadas e; (iii) os mármores e dolomitos são as rochas que apresentam menor resistência.

Sendo assim, pela diversidade litológica da Serra do Gandarela, a área herdou um patrimônio geomorfológico muito importante, especialmente do ponto de vista científico e paisagístico. As diferenças na elevação do terreno (Figura 3) são marcantes de um contexto geológico para outro, além de proporcionar inúmeras feições no relevo. A Cachoeira de Santo Antônio, por exemplo, um dos níveis de base da Bacia do Ribeirão da Prata, está em uma altitude de aproximadamente $840 \mathrm{~m}$, enquanto algumas de suas cabeceiras estão entre 1.500 a $1.600 \mathrm{~m}$ de altitude. 
Na passagem de uma litologia para outra, especialmente nas transições envolvendo rochas da Formação Cauê (Supergrupo Minas) observa-se um predomínio de um relevo escarpado, com declividades acima de 65\%, tanto para o interior quanto para fora da Sinclinal (Figuras 4 e 5).

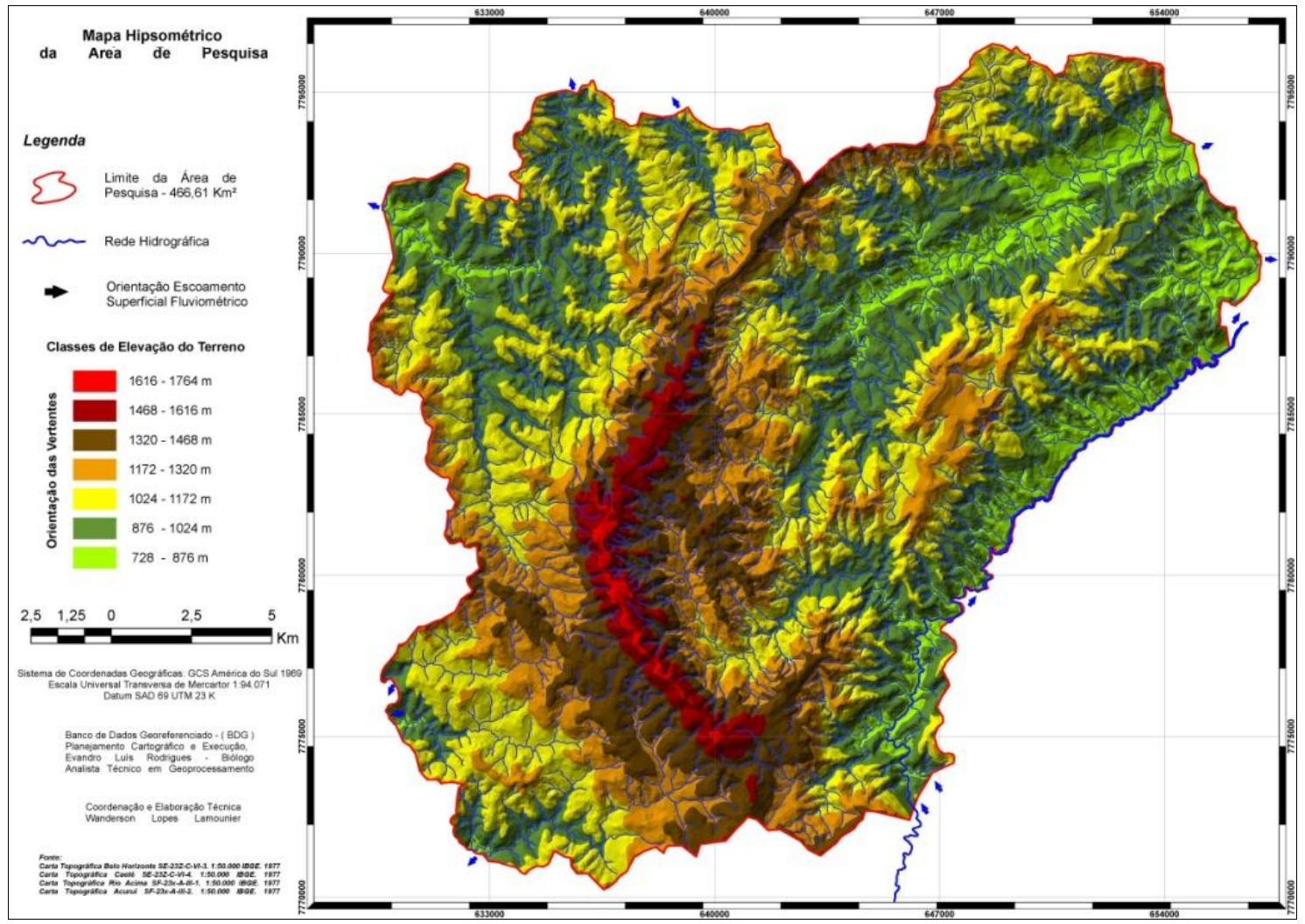

Figura 3: Mapa hipsométrico da área de pesquisa

Já o interior da sinclinal é visivelmente marcado pelos processos de dissecação, que vem deixando o relevo, presente nas rochas carbonáticas da Formação Gandarela, totalmente entalhado (Figura 6).

Encontra-se ainda, na Serra do Gandarela, sobretudo nas rochas ferríferas do Grupo Itabira, inúmeras cavernas. Apenas na aba noroeste da região já foram levantadas 74 cavidades, sendo que, desse total, 44 foram investigadas mais profundamente (AMPLO CONSULTORIA, 2009). Segundo a avaliação do ICMBio (2010) pelo menos 04 dentre estas 44 cavidades catalogadas possuem características para serem classificadas como de relevância máxima. Considerando-se que a área onde foram prospectadas as 74 cavidades é pequena em relação à área ocupada pelas formações ferríferas, é possível que o número de cavidades naturais na região seja muito mais elevado. 


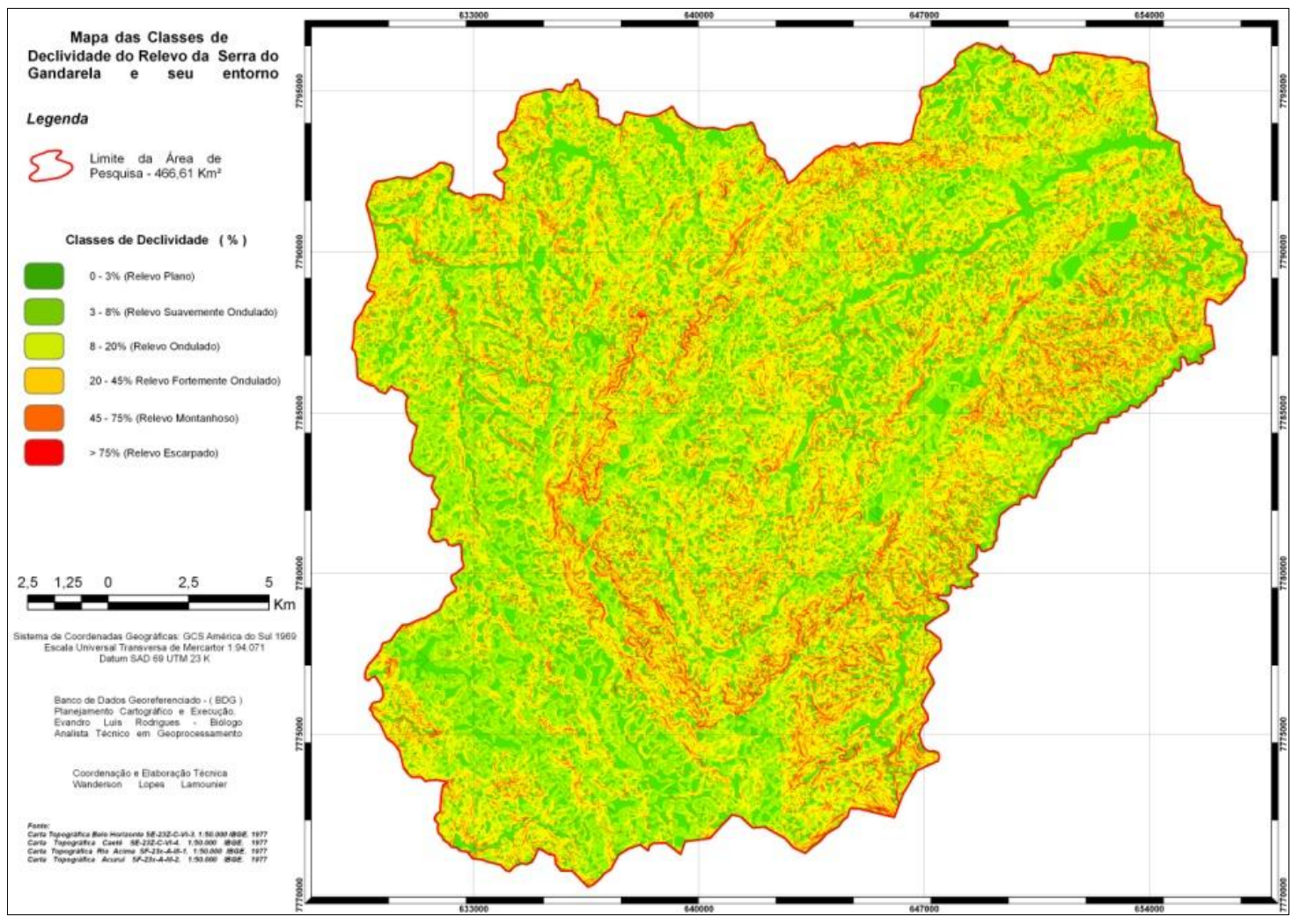

Figura 4: Mapa das classes de declividade do relevo da área pesquisada

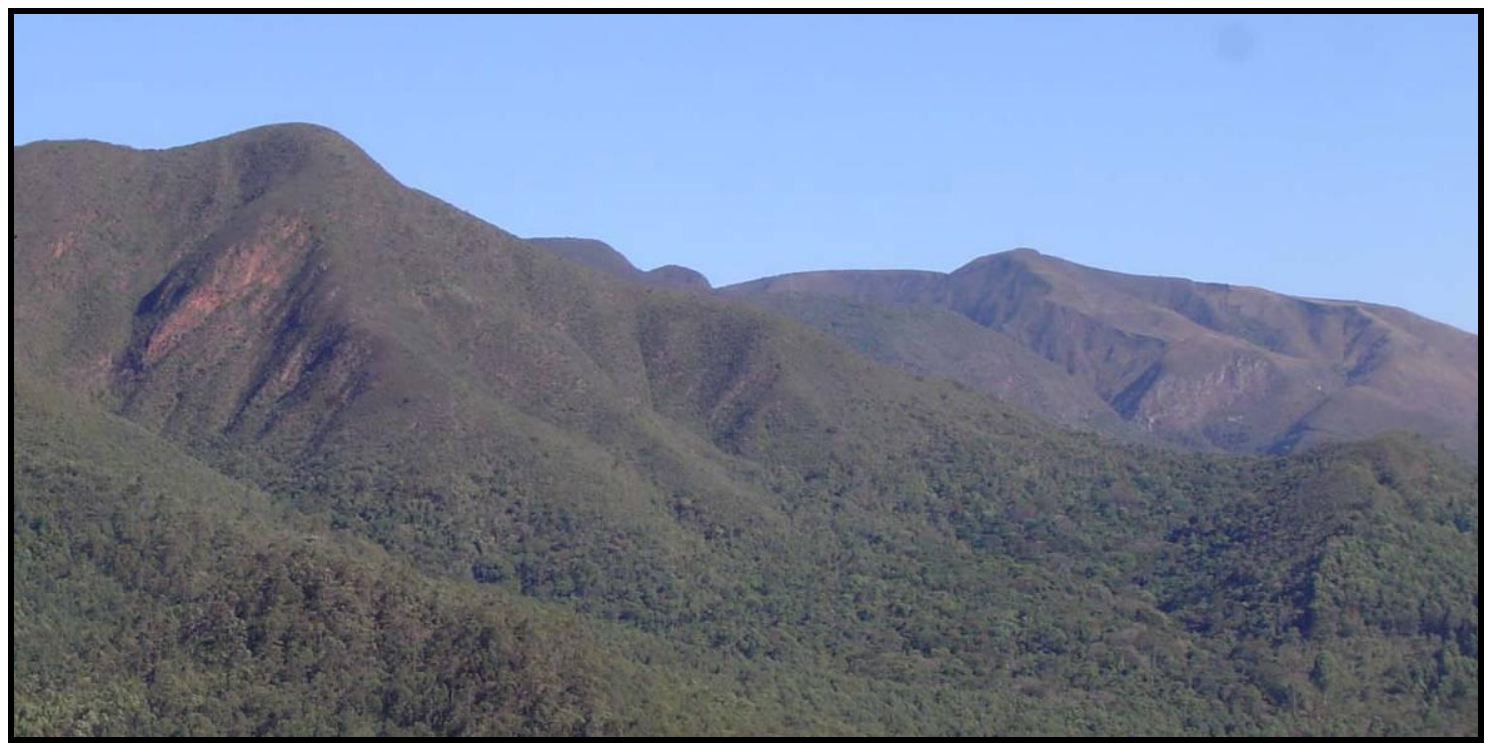

Figura 5: Relevo escarpado em transição litológica (parte alta: rochas ferríferas da Formação Cauê (Supergrupo Minas); parte baixa: rochas do Grupo Nova Lima (Supergrupo Rio das Velhas). Fonte: autor

Além da grande quantidade de cavidades, na aba leste da sinclinal pode ser encontrado um relevo característico de um ambiente cárstico. No local observam-se inúmeras dolinas 
Serra do Gandarela: Possibilidade de Ampliação das Unidades de Conservação no Quadrilátero Ferrífero-MG

Wanderson Lopes Lamounier, Vilma Lúcia Macagnan Carvalho e André Augusto Rodrigues Salgado

formadas pela dissolução das rochas carbonáticas presentes no alinhamento da serra. Periodicamente essas dolinas são preenchidas de água formando lagoas naturais.

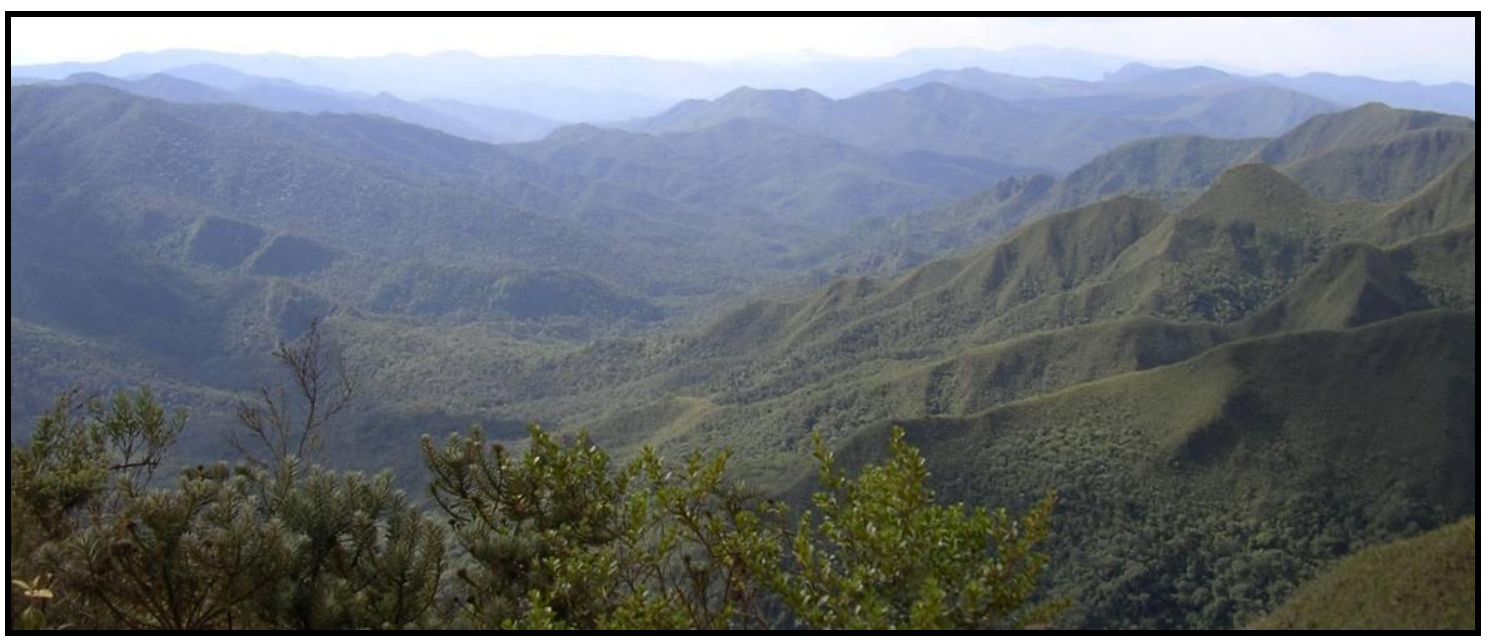

Figura 6: Relevo dissecado formando escarpas e topos de morros aguçados no interior da Sinclinal Gandarela. Fonte: autor

Mesmo com uma breve descrição é notável a diversidade de ambientes e feições geomorfológicas dentro da área de estudo. Toda essa potencialidade é ainda pouco conhecida e explorada em termos de pesquisas científicas, projetos envolvendo práticas de educação ambiental e trabalhos de campo. Trata-se de um laboratório a céu aberto com fácil visualização de estruturas geológicas, como falhas, dobras, controles estruturais, além de capturas de drenagem, anfiteatros suspensos, e muitos outros processos. Poucos são os lugares que realmente proporcionam esta infinidade de observações e descrições, tanto na geomorfologia estrutural, processos e formas de vertentes, geomorfologia fluvial e, ainda, numa abordagem envolvendo a geomorfologia cárstica. No mais, do ponto de vista turístico, o relevo da área tem todos os ingredientes necessários para a atração do grande público, que podem contar com todas as variantes do turismo ligado ao meio natural: ecoturismo, geoturismo, turismo de aventura, entre outros. A valorização dos aspectos cênicos da paisagem, sobretudo das feições geomorfológicas, tem fomentado o turismo em muitos lugares no Brasil e em todo o mundo.

Há de se destacar na área investigada um rico e importante patrimônio hídrico, observado na grande quantidade de nascentes e córregos (Figura 7). Toda essa grandiosidade de águas superficiais é fruto de um imenso potencial subterrâneo observado na área. Segundo o 
IBRAM (2003), é de se destacar regionalmente os aqüíferos encontrados nas rochas itabiríticas da Formação Cauê, pois possuem um grande potencial de acumulação. Para Davis et al. (2005), a região do Gandarela constitui uma das maiores reservas hídricas subterrâneas do Quadrilátero Ferrífero. Esses aquíferos são de extrema importância para as áreas de drenagem das bacias ali presentes.

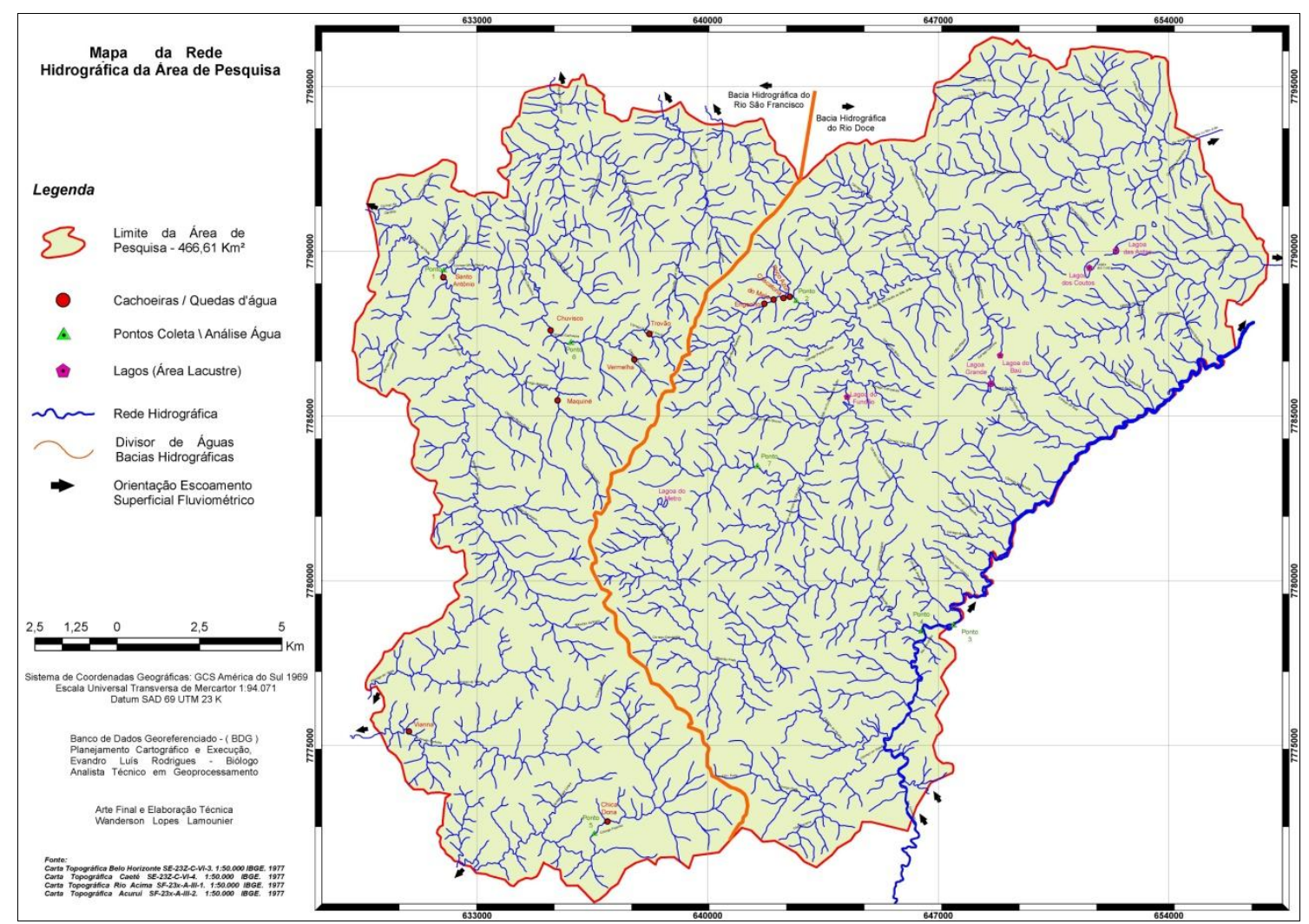

Figura 7: Mapa da rede hidrográfica da área pesquisada (muitas cachoeiras presentes na área não estão representadas no mapa).

As análises físico-químicas da água, realizadas em 07 pontos, especialmente em termos de metais pesados, demonstraram que além da quantidade a de se destacar a qualidade dessas águas, pois apresentaram, em comparação com os parâmetros da Resolução CONAMA (2005), resultados compatíveis com a Classe Especial ou Classe 1. Portanto, de uma forma geral, todos os cursos d'água possuem características que Ihes confere uma qualidade incontestável. Essa qualidade das águas da Serra do Gandarela é fundamental para sustentar a qualidade da água do Rio das Velhas e Piracicaba, que se encontram, em muitos trechos, bem impactada.

Sendo o relevo da área fruto de processos de erosão diferencial, sobre uma litologia altamente diversificada, como mencionado anteriormente, observa-se a presença de um 
relevo escalonado e inúmeras rupturas de declive. A associação desse relevo com o rico patrimônio hídrico da Serra do Gandarela favoreceu a ocorrência de dezenas de cachoeiras na região.
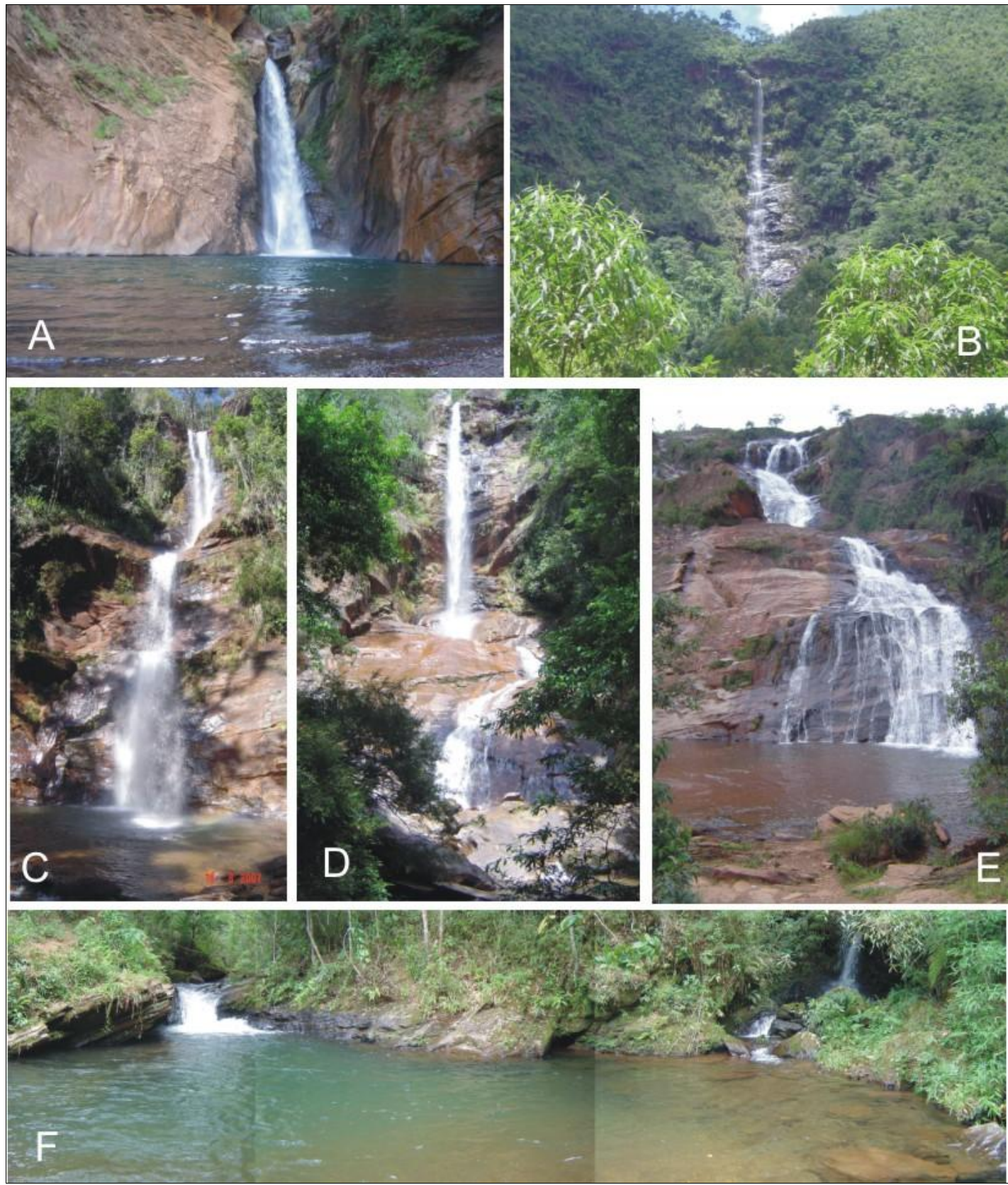

Figura 8: Alguns exemplos de cachoeiras presentes no interior da área de estudo. A - Cachoeira de Santo Antônio; B - Cachoeira Vermelha; C - Cachoeira de Maquiné; D - Cachoeira do Chuvisco; E - Cachoeira Chica Dona; F - Quedas d'água do Córrego Maria Casimira. Fonte: autor

A maioria das cachoeiras não são exploradas turisticamente. Isto ocorre graças a dificuldade de acesso e informações de localização, questões observadas durante os levantamentos na área. Há de se destacar as cachoeiras de Santo Antônio (Figura 8A), Cachoeira Vermelha (Figura 8B), de Maquiné (Figura 8C), do Chuvisco (Figura 8D), todas dentro do município de 
Caeté. No município de Itabirito e Rio Acima são bem conhecidas as cachoeiras Chica Dona (Figura 8E) e dos Viana, respectivamente. Já em Santa Bárbara são inúmeras quedas d'água no Córrego Maria Casimira (Figura 8F) próximo ao Povoado de André do Mato Dentro. Alem dessas, muitas outras cachoeiras podem ser observadas na área, especialmente no Ribeirão da Prata.

Todo esse conjunto paisagístico é de suma importância para a realização de atividades recreativas em contato com a natureza. A busca de ambientes naturais para descanso e lazer tem crescido cada vez mais a cada ano. Nesse aspecto, a Serra do Gandarela tem se mostrado, diante do que já foi levantado, uma área com enorme potencial natural, passível de realização de diferentes atividades.

\section{O Ambiente Biológico da Serra do Gandarela}

Em termos de vegetação a região do Serra do Gandarela apresenta um mosaico de formações vegetais. Essa diversidade de fitofisionomias ocorre em virtude de ser uma área de transição entre os Biomas Mata Atlântica e Cerrado. Além disso, segundo Lamounier et al. (2008), o padrão de distribuição da vegetação da Serra do Gandarela parece ser condicionado pelo substrato litológico e pelo relevo. Pode ser encontrado na área campos rupestres, tanto ferruginosos quanto quartzíticos; campo limpo e campo sujo e a Floresta Estacional Semidecidual (Figura 9).

Dentre essa variedade de formações campestres, há de se destacar os campos rupestres, pois entre todos os ecossistemas brasileiros é o que apresenta o maior índice de endemismo (JOLY apud BRANDT, 2005). Segundo Mendonça e Lins (2000), além da presença de espécies de ocorrência restrita, essa vegetação possui grande valor paisagístico, elevada diversidade e suas plantas possuem uma riqueza de adaptações morfológicas e fisiológicas que lhes permitem sobreviver às condições extremas de temperatura, pobreza dos solos e baixa disponibilidade de água.

Para Carmo (2010) a Sinclinal Gandarela ainda abriga a maior área de canga do Quadrilátero Ferrífero, em torno de 40\%, e que as cangas do Quadrilátero Ferrífero constituem áreas de alto valor para a conservação, pois apresentam atributos importantes, a raridade e o endemismo de plantas. 


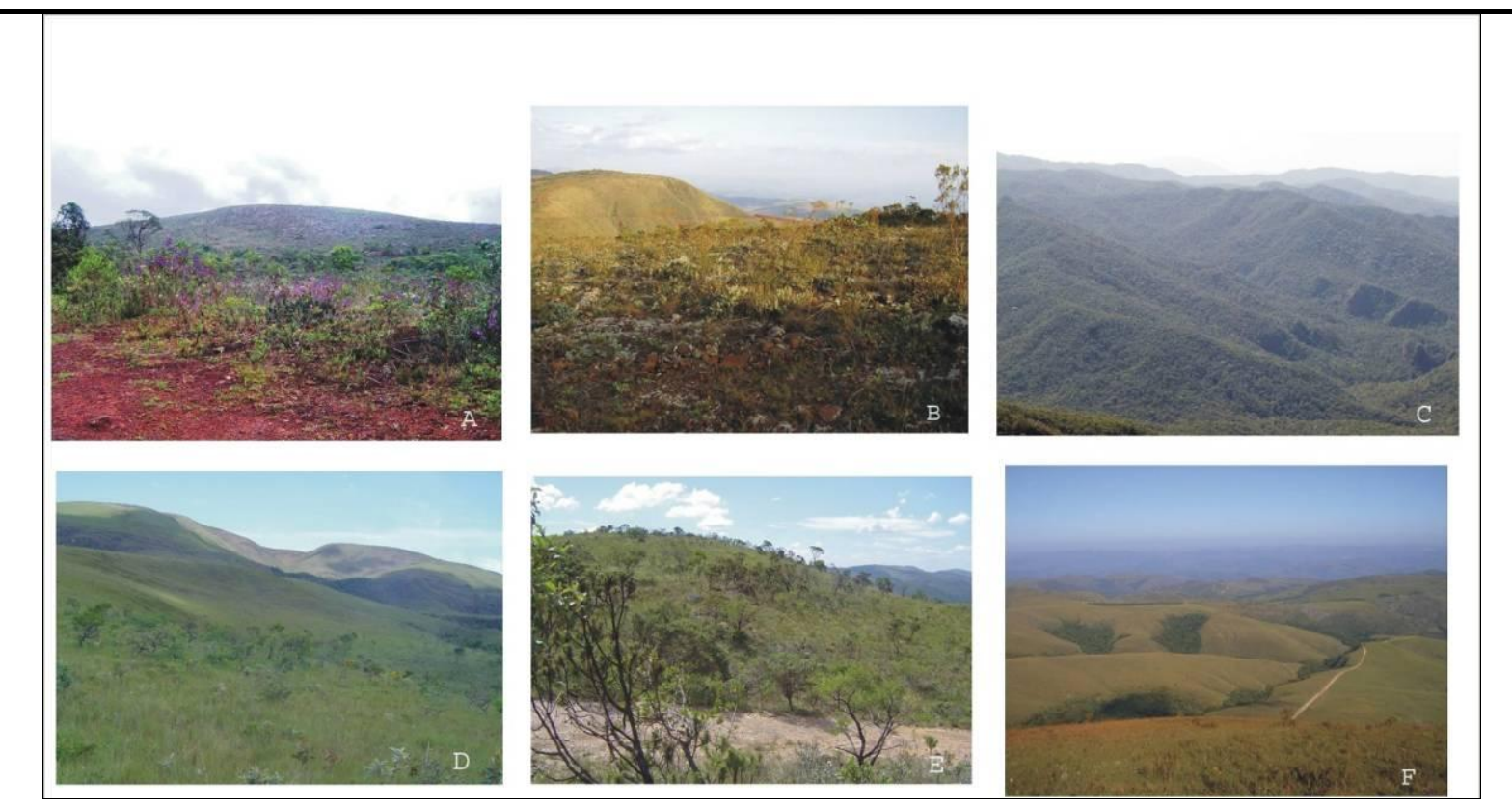

Figura 9: A - campo rupestre quartzítico (parte alta) e campo rupestre em canga (parte baixa); B - campo rupestre hematítico; C - Floresta Estacional Semidecidual; D - campo limpo; E - campo sujo (Grupo Nova Lima); F - campo limpo e matas de galeria. Fonte: autor

Dentre as espécies presentes na área de pesquisada, de acordo com os EIA-RIMAs investigados, e também inseridas na lista vermelha da flora, segundo a Fundação Biodiversitas (2007), estão:

- Hippeastrum sp. (lírio-das-pedras - encontrada em campo rupestre);

- Evolvulus sp. (encontrada em campo rupestre);

- Ipomoea sp. (encontrada em campo rupestre);

- Paepalanthus sp. (sempre-viva - encontrada em campo e campo rupestre);

- Vellozia sp. (canela-de-ema - encontrada em campo rupestre)

- Baccharis sp. (encontrada em campo);

- Byrsonima sp. (encontrada em campo);

- Peixotoa sp. (encontrada em campo);

- Aspidosperma sp. (peroba - encontrada em mata);

- Philodendron sp. (imbé - encontrada em mata);

- Blechnum sp. (encontrada em mata);

- Sphagnum sp. (encontrada em mata);

- Machaerium sp. (jacarandá - encontrada em mata).

Família Bromeliaceae:

- Dyckia sp. (encontrada em campo rupestre); 
- Vriesea sp. (encontrada em campo rupestre);

- Bilbergia sp. (encontrada em mata).

Família Orchidaceae (orquídeas):

- Bifrenaria sp. (encontrada em campo rupestre);

- Bulbophyllum sp. (encontrada em campo rupestre);

- Encyclia sp. (encontrada em mata).

Dentre as poucas classificações até o nível de espécie realizadas nesses estudos, algumas também constam na lista vermelha, todas incluídas na categoria de extinção "vulnerável":

- Lychnophora pinaster (encontrada em campo rupestre);

- Dalbergia nigra (jacarandá-caviúna ou cabiúna - encontrada em mata);

- Ocotea odorífera (sassafrás - encontrada em mata);

- Melanoxylon brauna (braúna - encontrada em mata);

- Lychnophora ericoides (arnica-do-campo - encontrada em campo ou campo rupestre);

- Oncidium warmingii (Orchidaceae encontrada em campo rupestre).

O modo que a flora está apresentada nos EIA-RIMAs demonstra a grande dificuldade por parte dos especialistas em classificar as espécimes. A maioria delas foi classificada até gênero, não sendo identificada a espécie. A falta dos nomes científicos impossibilitou a identificação das mesmas na lista de espécies ameaçadas de extinção.

Apesar das dificuldades na classificação, alguns gêneros encontrados na área, que englobam um grande número de espécies, também são citados por várias vezes na lista de espécies ameaçadas de extinção. Grande parte das espécies incluídas nesses gêneros está inserida na categoria criticamente ameaçada de extinção. Outras foram apontadas como em perigo de extinção ou vulneráveis e, ainda, com deficiência de dados para algum tipo de inferência.

Num primeiro momento, o número de espécies envolvidas no processo de extinção parece ser pequeno na área. Mas ao relacionar esses dados com a pequena área utilizada nesses levantamentos essas informações tomam outras dimensões. O que mais preocupa são as espécies não identificadas nesses EIA-RIMAs, que contêm apenas a informação do gênero a que pertencem, pois a maioria está criticamente ameaçada de extinção.

Em termos de fauna os EIA-RIMAs analisados citam que a área possui uma rica biodiversidade. Além disso, em muitos casos, alguns animais descritos, principalmente da classe dos anfíbios, parecem tratar de espécies ainda não conhecidas na literatura. As 
principais espécies descritas nesses documentos, presentes também na nova lista de espécies da fauna ameaçadas de extinção no Estado de Minas Gerais, segundo a Fundação Biodiversitas (2007), foram:

Mamíferos: Felis pardalis ou Leopardus pardalis (jaguatirica); Felis concolor ou Puma concolor (onça-parda); Panthera onça (onça-pintada); Callicebus personatus (sauá, guigó primata); Chrysocyon brachyurus (lobo-guará).

Além desses mamíferos ameaçados de extinção, há de se destacar a presença do Tamandua tetradactyla (tamanduá-mirim), que estava ameaçado na última lista vermelha e foi reclassificado como não ameaçado na nova lista, além de outras duas espécies, Dasypus septemcinctus (tatu-mulita) e Puma yagouaroundi (cachorrinho-do-mato), ambas com informações insuficientes para serem incluídas em alguma categoria de ameaça de extinção. Vale ainda ressaltar, que todas essas espécies relacionadas foram citadas nos diferentes documentos consultados.

Avifauna: Leucopternis polionotus (Gavião-pombo-grande); Odontophorus capueira (uru, capueira); Laniisoma elegans (chibante); Phibalura flavirostris (tesourinha-da-mata); Rhynchocyclus olivaceus (bico-chato-grande); Lipaugus lanioides (tropeiro-da-serra, cricrió) e Pyroderus scutatus (pavó, pavão-do-mato) estão quase ameaçadas de extinção (FUNDAÇÃO BIODIVERSITAS, 2007). Já a espécie Penelope obscura (jacuaçu) foi reavaliada como não ameaçada de extinção.

$\mathrm{Na}$ verdade, as espécies mencionadas acima, tanto da fauna quanto da flora servem apenas para ilustrar um pouco do contexto biótico da área, pois esses EIA-RIMAs representam menos de $1 \%$ do total da área de pesquisa. Mesmo sendo pequenos pontos de amostragem, esses dados revelam a potencialidade e ao mesmo tempo a fragilidade da região. Sendo assim, é essencial a realização de pesquisas para se conhecer de forma mais íntima a grande diversidade de espécies que compõe a Serra do Gandarela. Não se trata de preservar uma ou duas espécies, mas uma área grande, representativa, que aparenta ter uma rica biodiversidade.

\section{A Serra do Gandarela no Contexto das Áreas Protegidas}

A análise ambiental realizada na Serra do Gandarela permitiu identificá-la como prioritária para a conservação, pois ela reúne todos os ingredientes necessários para a criação de novas unidades de conservação. Possui uma paisagem diferenciada com uma diversidade de 
formações físicas, objetivo que motivou a criação das primeiras áreas protegidas em todo o mundo. Fora isso, apresenta uma rica biodiversidade, ainda pouca revelada e muito ameaçada pela ação antrópica. Além do mais, o potencial hídrico de uma área, apesar de não ser muito usado como critério para seleção de novas UCs, deve se tornar indispensável em novas avaliações, e, como já foi discutido, a Serra do Gandarela possui uma enorme quantidade de água superficial, além de uma vasta reserva subterrânea.

Sendo assim, dentro de toda a área investigada foi possível selecionar uma porção considerada de maior relevância (Figura 10). Toda sua extensão apresenta características diversificadas e com diferentes particularidades, bem como uma área pouco fragmentada e preservada, com ocorrência de vários tipos de ecossistemas, e consequentemente uma diversidade de espécies. Franklin (1993) cita que as áreas tropicais possuem uma alta biodiversidade, muito das vezes desconhecida, e que o ideal é selecionar áreas baseadas não na distribuição das espécies, mas na distribuição dos ecossistemas presentes nela, pois desta forma as interações ecológicas serão preservadas.

Nessa busca de selecionar uma área considerada representativa, Primack e Rodrigues (2001) citam que é mais viável e mais importante agrupar numa mesma área hábitats diversificados, incluindo montanhas, lagos, florestas, etc., pois possibilita a ocorrência de um maior número de espécies, do que selecionar áreas com hábitats uniformes. Essa idéia foi compartilhada na área de estudo, uma vez que dentro dos limites estabelecidos encontra-se uma variedade enorme de ambientes.

Além disso, procurou-se delimitar uma área maior possível, pois de acordo com os estudos biogeográficos, as áreas maiores normalmente possuem um número maior de habitats, consequentemente um grande número de nichos e de espécies (WILCOX, 1980). Wilson e Willis (1975) também citam que reservas individuais devem possuir o maior tamanho possível, principalmente para preservar espécies mais vulneráveis, como mamíferos e pássaros.

Nesse sentido, de acordo as informações obtidas sobre a fauna da Serra do Gandarela foi possível identificar a presença de espécies de mamíferos de grande porte. Assim, como um dos objetivos para a área é o de preservar a fauna local e regional, o tamanho dessa reserva tem papel fundamental na manutenção dessas espécies, uma vez que já foi comprovado que certos mamíferos, como lobo-guará e onça pintada, não sobrevivem por longo tempo em reservas pequenas. 


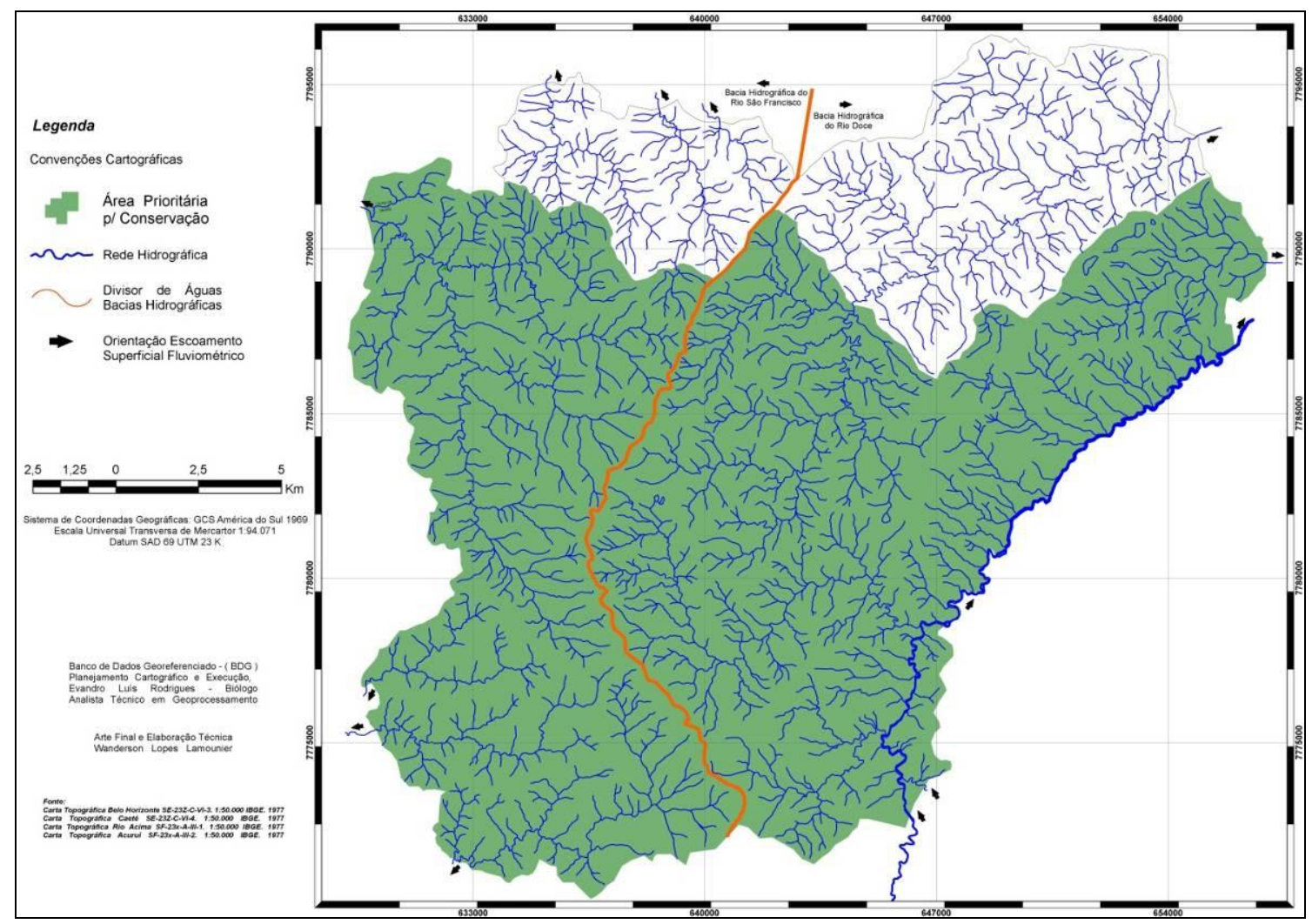

Figura 10: Mapa da área de estudo apresentando a porção considerada prioritária para a conservação (área em verde).

Como já discutido até aqui, a parte selecionada de toda a área investigada neste trabalho possui características indiscutíveis para se tornar uma área protegida. Assim, baseado no SNUC e nas condições ambientais levantadas, foi possível identificar três categorias de unidades de conservação mais apropriadas para a área: uma de proteção integral (Parque) e duas de uso sustentável (Reserva de Desenvolvimento Sustentável e Área de Relevante Interesse Ecológico) (Figura 11).

A maior parte da área (área verde no mapa), com aproximadamente $272,13 \mathrm{~km}^{2}$ (27.231 ha), por todas as qualidades observadas em campo e já descritas anteriormente, se enquadra perfeitamente na categoria Parque. De acordo com o SNUC, as áreas destinadas aos parques têm por objetivo preservar seus ecossistemas naturais de grande relevância ecológica e beleza cênica, realizar pesquisas científicas, atividades de educação e interpretação ambiental e turismo ecológico (BRASIL, 2000). Todos os propósitos e objetivos para a criação desse tipo de categoria são encontrados nessa porção da área estudada. Além do mais, essa área indicada para a categoria Parque não possui quase nenhuma ocupação humana, condição essencial na criação de parques no Brasil. 
A segunda parte (área central), com 43,57 km² (4.357 ha), inclui as comunidades de André do Mato Dentro, Cruz dos Peixoto, Conceição do Rio Acima e Galego. Pelas atividades já desenvolvidas pelos moradores e pela preocupação com as questões ambientais, essa parcela da área estudada se insere perfeitamente nos objetivos de uma Reserva de Desenvolvimento Sustentável. Segundo o SNUC, essa categoria deve incluir áreas naturais que abrigam populações tradicionais, que utilizam os recursos naturais de forma sustentável, mantendo as condições ecológicas ambientais, que possam valorizar, conservar e aperfeiçoar seus conhecimentos e técnicas de manejo do ambiente (BRASIL, 2000). A população não foi consultada sobre a aceitação da criação de uma reserva na área, mas ficou claro durante os trabalhos de campo, a necessidade da sua preservação pelos moradores locais, em especial no Povoado de André do Mato Dentro, onde já se desenvolvem práticas agroecológicas, desenvolvimento de agricultura familiar e atividades de apicultura. A população conhece as características dos ecossistemas locais e parece utilizar formas pouco impactantes de utilização e exploração de seus recursos. Além de incentivar a conservação e a busca de práticas de exploração controlada, essa Reserva de Desenvolvimento sustentável poderá se constituir como uma zona de amortecimento para as demais unidades de conservação próximas.

Já a parte destacada na porção leste da área, com 44,59 km² (4.459 ha), possui grande vegetação nativa e muitas lagoas naturais importantes para a fauna. No local foi observada a presença de muitos animais, questão também apresentada pelos moradores da região. Nesse sentido, correlacionando essas informações com as do SNUC, conclui-se que esse setor da área de estudo se enquadra muito bem nas propostas de uma Área de Relevante Interesse Ecológico, categoria ainda não criada no Estado. Esse tipo de UC, de acordo com Brasil (2000), possui geralmente pequena extensão de área e pouca ou quase nenhuma ocupação humana, mas com características naturais importantes ou que abriga exemplares significativos da biota local e regional. Essa unidade poderá ser de grande importância na manutenção dos ecossistemas ali presentes uma vez que propõe uma política de desenvolvimento sustentável. E o fato de suas terras não requererem o domínio público poderá facilitar a sua criação.

Desta forma, esse mosaico de áreas protegidas poderá trazer grandes benefícios a esta parte do Quadrilátero Ferrífero, tanto do ponto de vista da conservação quanto da promoção de 
novas atividades econômicas mais sustentáveis, como o turismo, além da possibilidade do desenvolvimento de trabalhos científicos e projetos voltados para educação ambiental.

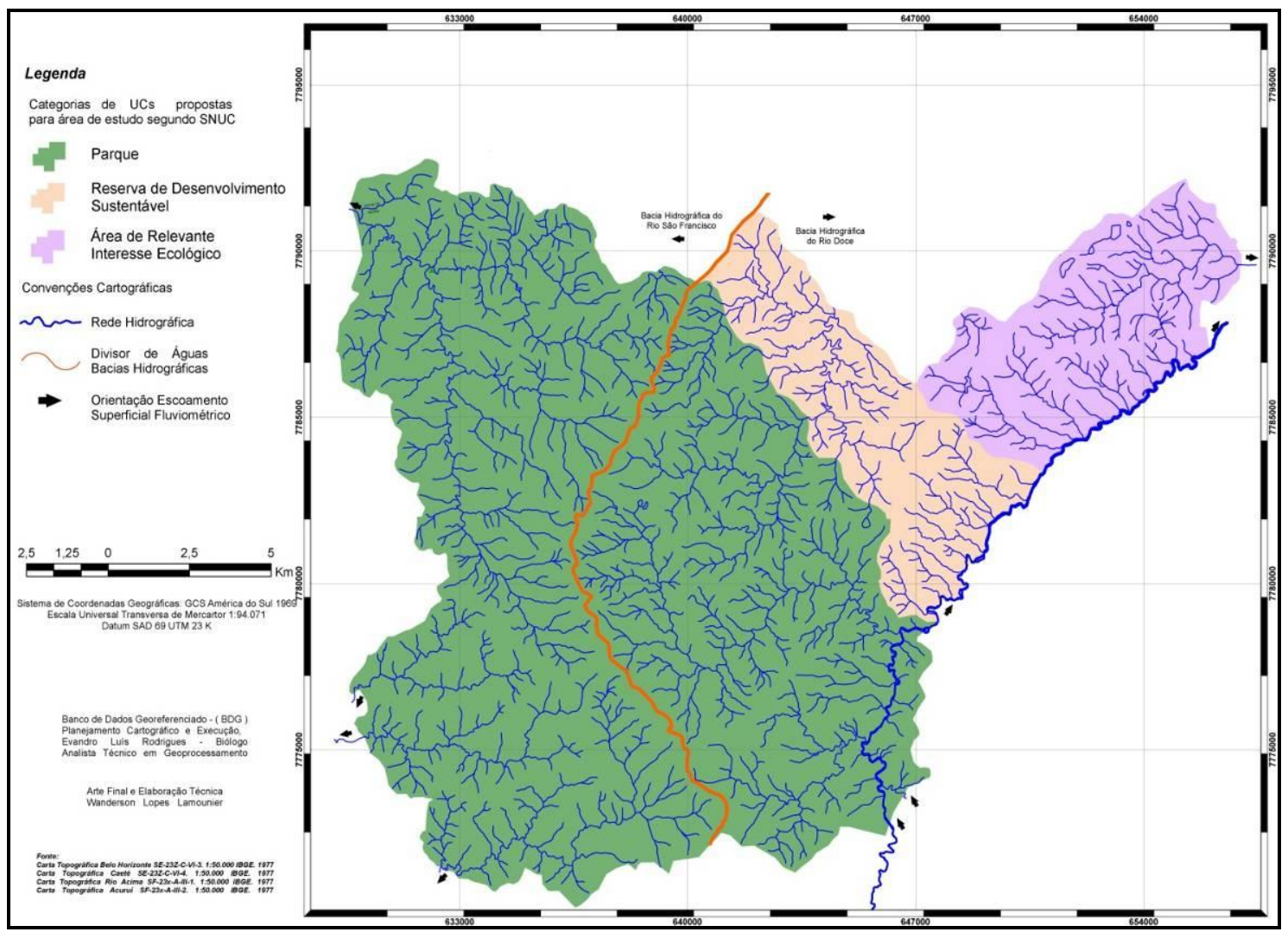

Figura 11: Mapa com indicação de categorias de UCs passíveis de criação na área selecionada.

\section{CONCLUSÕES}

A partir de todo levantamento realizado e de todas as informações registradas ao longo desse trabalho, as seguintes considerações podem ser feitas:

1. O Quadrilátero Ferrífero, considerado como de importância biológica especial e com grande destaque pela presença de ambientes diferenciados em todo o estado, necessita ser mais preservado. Há muito tempo a região vem sendo explorada economicamente, levando à destruição de hábitats, fragmentação dos ecossistemas, poluição de recursos hídricos, descaracterização da paisagem e, consequentemente, a perda da biodiversidade.

2. A Serra do Gandarela e seu entorno pode ser considerada como prioritária para a conservação, pois possui muitas características e qualidades, tais como:

- É a área mais conservada no interior do Quadrilátero Ferrífero, com extensa cobertura vegetal de Floresta Semidecídua (Mata Atlântica); 
- Possui um dos ambientes mais ricos e complexos, não só do Quadrilátero, mas de todo o Estado, em termos geológicos e geomorfológicos. Trata-se de um laboratório a céu aberto para estudos científicos, projetos de educação ambiental, promoção do turismo, etc.;

- Abriga em seu interior uma infinidade de nascentes e córregos com qualidade para serem considerados de classe especial, além de serem importantíssimos para o abastecimento regional e para a manutenção dos cursos d'água a jusante da área;

- Possui uma diversidade de cascatas e cachoeiras proporcionadas pelo relevo acidentado. Além da bela paisagem, elas são fundamentais para o desenvolvimento do turismo na área, como ocorre nos Parques Nacionais da Serra da Canastra e Serra do Cipó, por exemplo;

- Concentra grande diversidade de ecossistemas e ambientes, consequentemente uma grande variedade de espécies.

- Apresenta muitas espécies endêmicas e ameaçadas de extinção, tanto da flora como na fauna, especialmente nos campos rupestres e Mata Atlântica;

- Tem pouca ocupação humana, porém fortes pressões antrópicas que tendem a aumentar consideravelmente.

3. Grande parte da área estudada possui características que favorecem a criação de unidades de conservação naquela porção do Quadrilátero Ferrífero. A área mais conservada dentro dos limites estudados, por exemplo, tem grande potencial para se transformar em um Parque Nacional. Sua criação seria de fundamental importância para complementar de forma mais eficiente o sistema regional de unidades de conservação.

\section{REFERÊNCIAS BIBLIOGRÁFICAS}

AMBIENTE CONSULTORIA. Estudo de Impacto Ambiental (EIA) e Relatório de Impacto Ambiental (RIMA). Região Gandarela. Santa Bárbara e Rio Acima, 1995. Disponível no arquivo da FEAM.

AMERICAN PUBLIC HEATH ASSOCIATION. Standart methods for the examination of water and wastewater. 19. ed. Washington: American Public Health Association, 1995.

AMPLO CONSULTORIA. Relatório de Impacto Ambiental (RIMA). Projeto Mina Apolo. Belo Horizonte, 2009.

BRANDT Meio Ambiente. Estudo de Impacto Ambiental (EIA). Mina Santa Isabel. Itabirito, 2005. Disponível no arquivo da FEAM. 
BRASIL. Lei no 9.985, de 18 de julho de 2000. Regulamenta o art. 225, § 1으, incisos I, II III e IV da Constituição Federal, institui o Sistema Nacional de Unidades de Conservação da Natureza e dá outras providências. Brasília: Senado Federal, 2000.

CARMO, F. F. Importância Ambiental e Estado de Conservação dos Ecossistemas de Cangas no Quadrilátero Ferrífero e Proposta de Áreas-Alvo para a Investigação e Proteção da Biodiversidade em Minas Gerais. 2010, 90 f. Dissertação (Mestrado em Ecologia, Conservação e Manejo da Vida Silvestre) - Universidade Federal de Minas Gerais, Belo Horizonte.

CEMA - Consultoria e Engenharia do Meio Ambiente Ltda. Estudo de Impacto Ambiental (EIA). Projeto Bocaina - Mineração Brumal Ltda. Santa Bárbara, 1996. Disponível no arquivo da FEAM.

CEMA - Consultoria e Engenharia do Meio Ambiente Ltda. Estudo de Impacto Ambiental (EIA). Projeto Ouro Caeté - Caeté e Santa Bárbara. CVRD, 1994. Disponível no arquivo da FEAM.

CONSELHO NACIONAL DO MEIO AMBIENTE - CONAMA - Resolução no 357, de 17 de março de 2005. Dispõe sobre a classificação dos corpos de água e diretrizes ambientais para o seu enquadramento, bem como estabelece as condições e padrões de lançamento de efluentes, e dá outras providências. Brasília, 18 de março de 2005.

DRUMMOND, G. M.; MARTINS, C. S.; MACHADO, A. B. M.; SEBAIO, F. A.; ANTONINI, Y. (org.). Biodiversidade em Minas Gerais: Um Atlas para sua Conservação. Belo Horizonte: Fundação Biodiversitas, 2005, 222 p.

FRANKLIN, J. F. Preserving biodiversity: species, ecosystems, or landscapes? Ecological Applications, v. 3, p. 202-205, 1993.

FUNDAÇÃO BIODIVERSITAS. Revisão das Listas das Espécies da Flora e da Fauna Ameaçadas de Extinção do Estado de Minas Gerais: relatório final, volume 2 e 3. Belo Horizonte: Fundação Biodiversitas, 2007.

INSTITUTO BRASILEIRO DE GEOGRAFIA E ESTATÍSTICA - IBGE. Departamento de cartografia Carta do Brasil (Escala: 1:50.000) - Carta Topográfica Belo Horizonte (SE-23Z-C-VI-3), 1977.

- Departamento de cartografia - Carta do Brasil (Escala: 1:50.000) - Carta Topográfica Caeté (SE-23Z-C-VI-4), 1977.

- Departamento de cartografia - Carta do Brasil (Escala: 1:50.000) - Carta Topográfica Rio Acima (SF-23X-A-III-1), 1977.

Departamento de cartografia - Carta do Brasil (Escala: 1:50.000) - Carta Topográfica Acuruí (SF-23X-A-III-2), 1977.

INSTITUTO CHICO MENDES DE CONSERVAÇÃO DA BIODIVERSIDADE (ICMBio). Proposta de Criação do Parque Nacional Serra do Gandarela. Setembro, 2010.

LAMOUNIER, W. L.; SALGADO, A. A. R.; CARVALHO, V. L. M.; MARENT, B. R. As Correlações entre Geologia e Distribuição da Cobertura Vegetal e Uso do Solo na Serra do Gandarela, 
Quadrilátero Ferrífero-MG. In: VII Simpósio Nacional de Geomorfologia (II Encontro LatinoAmericano de Geomorfologia). Belo Horizonte, 2008.

MAIZATTO, J. R. Análise bioestratigráfica, paleoecológica e sedimentológica das bacias terciárias do Gandarela e Fonseca - Quadrilátero Ferrífero - Minas Gerais, com base nos aspectos palinológicos e sedimentares. 2001, 333 f. Tese (Doutorado em Evolução Crustal e Recursos Naturais) - Departamento de Geologia, Universidade Federal de Ouro Preto, Ouro Preto.

MENDONÇA, M. P.; LINS, L. V. (Orgs.). Lista Vermelha das Espécies Ameaçadas de Extinção da Flora de Minas Gerais. Belo Horizonte: Fundação Biodiversitas/ Fundação Zoo-Botânica de Belo Horizonte. 2000. 47 p.

PRIMACK, R. B.; RODRIGUES, E. Biologia da Conservação. Londrina: E. Rodrigues, 2001, 327 p.

NICHO Engenheiros e Consultoria. Estudo de Impacto Ambiental (EIA). Mina de Gongo Velho (CVRD). Barão de Cocais, 2002. Disponível no arquivo da FEAM.

RUCHKYS, U. A. Patrimônio Geológico e Geoconservação no Quadrilátero Ferrífero, Minas Gerais: Potencial para a Criação de um Geoparque da UNESCO. 2007b, 211 f. Tese (Doutorado em Geologia) - Instituto de Geociências, Universidade Federal de Minas Gerais, Belo Horizonte.

SALGADO, A. A. R.; BRAUCHER, R.; VARAJÃO, C. A. C.; COLIN, F.; VARAJÃO, VARAJÃO, A. F. D. C.; NALINI JUNIOR, H. A. Relief evolution of the Quadrilátero Ferrífero (Minas Gerais, Brazil) by means of $\left({ }^{10} \mathrm{Be}\right)$ cosmogenic nuclei. Zeitschrift fur Geomorphologie, Berlin, v. 52, n.3, p. 317-323, 2008.

SALGADO, A. A. R.; VARAJÃO, C. A. C.; COLIN, F.; BRAUCHER, R.; NALINI JUNIOR, H. A.; VARAJÃO, A. F. D. O papel da denudação geoquímica no processo de erosão diferencial no Quadrilátero Ferrífero/MG. Revista Brasileira de Geomorfologia, Rio de Janeiro, v. 5 (1), p. 55-69, 2004.

WILCOX, B. A. Insular Ecology and Conservation. In: SOULÉ, M. E.; WILCOX, B. A. (Eds.) Conservation Biology: an evolutionary-ecological perspective. Sunderland, Massachusetts: Sinauer Associates, 1980, 95-117 p.

WILSON, E. O.; WILLIS, E. O. Applied Biogeography. In: CODY, M. L.; DIAMOND, J. M. (Eds.). Ecology and Evolution of Communities. Cambridge, Massachusetts: Harvard, Unversity Press, 1975, $545 \mathrm{p}$.

Artigo recebido em 17/10/2011.

Artigo aceito em 18/11/2011. 